\title{
Medication Reconciliation in Pediatric Cardiology Performed by a Pharmacy Technician: A Prospective Cohort Comparison Study
}

\author{
Carol Chan, Renée Woo, Winnie Seto, Sandra Pong, Tessie Gilhooly, and Jennifer Russell
}

\begin{abstract}
Background: Medication reconciliation reduces potential medication discrepancies and adverse drug events. The role of pharmacy technicians in obtaining best possible medication histories (BPMHs) and performing reconciliation at the admission and transfer interfaces of care for pediatric patients has not been described.
\end{abstract}

Objectives: To compare the completeness and accuracy of BPMHs and reconciliation conducted by a pharmacy technician (pilot study) and by nurses and/or pharmacists (baseline). The severity of identified unintentional discrepancies was rated to determine their clinical importance.

Methods: This prospective cohort comparison study involved patients up to 18 years of age admitted to and/or transferred between the Cardiology ward and the Cardiac Critical Care Unit of a pediatric tertiary care teaching hospital. A pharmacy resident conducted two 3-week audits: the first to assess the completeness and accuracy of BPMHs and reconciliation performed by nurses and/or pharmacists and the second to assess the completeness and accuracy of BPMHs and reconciliation performed by a pharmacy technician.

Results: The total number of patients was 38 in the baseline phase and 46 in the pilot period. There were no statistically significant differences between the baseline and pilot audits in terms of completion of BPMH (82\% [28/34] versus 78\% [21/27], $p=0.75)$ or completion of reconciliation $(70 \%$ [23/33] versus $75 \%[15 / 20], p=0.76)$ within $24 \mathrm{~h}$ of admission. Completeness of transfer reconciliation was significantly higher during the pilot study than at baseline $(91 \%$ [31/34] versus $61 \%$ $[11 / 18], p=0.022)$. No significant differences between the baseline and pilot audits were found in the proportions of patients with at least one BPMH discrepancy (38\% [13/34] versus 22\% [6/27], $p=0.27)$, at least one unintentional discrepancy upon admission (21\% [7/33] versus $10 \%$ $[2 / 20], p=0.46)$, or at least one unintentional discrepancy at the transfer interface $(6 \%[1 / 18]$ versus $3 \%[1 / 34], p=0.58)$. None of the 16 unintentional discrepancies were rated as causing severe patient discomfort or clinical deterioration.

Conclusions: A trained pharmacy technician can perform admission and transfer medication reconciliation for pediatric patients with completeness and accuracy comparable to those of nurses and pharmacists. Future studies should explore the sustainability and cost-effectiveness of this practice model.

\section{RÉSUMÉ}

Contexte : Le bilan comparatif des médicaments permet de réduire les possibles divergences au chapitre des médicaments ainsi que les éventuels événements indésirables liés aux médicaments. Le rôle des techniciens en pharmacie en ce qui a trait à l'obtention des meilleurs schémas thérapeutiques possibles (MSTP) et à la réalisation du bilan comparatif des médicaments au moment de l'admission et du transfert n'a pas encore été exposé chez l'enfant.

Objectifs : Comparer l'exhaustivité ainsi que l'exactitude des MSTP et des bilans comparatifs réalisés par une technicienne en pharmacie (étude pilote) à ceux réalisés par du personnel infirmier ou des pharmaciens (référence). Les divergences non intentionnelles observées ont été notées selon leur degré de gravité afin d'en établir l'importance clinique.

Méthodes : Cette étude de cohorte prospective comparative a été menée auprès de patients de 18 ans et moins ayant été admis à l'unité des soins intensifs coronariens ou au service de cardiologie, ou ayant été transférés de l'un à l'autre de ces deux services, dans un hôpital d'enseignement de soins tertiaires pour enfants. Une résidente en pharmacie a procédé à deux vérifications de trois semaines chacune. Celles-ci avaient pour but d'évaluer l'exhaustivité et l'exactitude des MSTP ainsi que des bilans comparatifs : la première évaluation portant sur le travail effectué par du personnel infirmier ou des pharmaciens et la seconde portant sur celui réalisé par une technicienne en pharmacie.

Résultats : Au total, la vérification a porté sur 38 patients au cours de la période de référence et 46 pour l'étude pilote. Aucune différence statistiquement significative n’a été notée entre les deux vérifications en ce qui a trait à l'obtention des MSTP (82\% [28/34] contre $78 \%$ [21/27], $p=0,75)$ ou à la réalisation des bilans comparatifs $(70 \%[23 / 33]$ contre $75 \%$ [15/20], $p=0,76$ ) dans les 24 heures suivant l'admission. L'exhaustivité dans la réalisation des bilans comparatifs au moment des transferts était nettement plus élevée dans l'étude pilote que durant la période de référence $(91 \%$ [31/34] contre $61 \%$ [11/18], $p=0,022)$. Aucune différence notable n'a été relevée entre les deux vérifications quant à la proportion de patients chez qui l'on a noté au moins une divergence dans le MSTP (38\% [13/34] contre $22 \%$ [6/27], $p=0,27)$, au moins une divergence non intentionnelle au moment de l'admission (21\% [7/33] contre $10 \%[2 / 20], p=0,46$ ) et au moins une divergence non intentionnelle au moment du transfert $(6 \%[1 / 18]$ contre $3 \%[1 / 34], p=0,58)$. Aucune 
Key words: medication reconciliation, best possible medication history, pharmacy technician, pediatrics, cardiology, cardiac critical care

Can J Hosp Pharm 2015;68(1):8-15 des 16 divergences non intentionnelles n’a été classée comme cause de gêne importante pour le patient ou d'une détérioration clinique de ce dernier.

Conclusions : Un technicien en pharmacie formé réalise des bilans comparatifs des médicaments, au moment de l'admission ou du transfert d'un enfant, d'une qualité comparable à celle du personnel infirmier ou des pharmaciens en ce qui a trait à l'exhaustivité et à l'exactitude. Les études ultérieures devraient porter sur la viabilité et le rapport coût-efficacité de ce modèle de pratique.

Mots clés : bilan comparatif des médicaments, meilleur schéma thérapeutique possible, technicien en pharmacie, pédiatrie, cardiologie, soins intensifs coronariens

\section{INTRODUCTION}

A complete and accurate medication history is a critical component of medication safety, and such histories are relevant to admission, transfer, and discharge interfaces of care in the hospital setting. Studies have consistently shown that incomplete or inaccurate medication histories lead to unintentional medication discrepancies with the potential to cause significant adverse drug events. ${ }^{1-4}$ Despite numerous studies in the adult population documenting the rates, types, and severity of medication discrepancies at hospital admission, similar data for pediatrics are scarce. ${ }^{1,5,6}$ Medication errors, particularly dosing errors, are more prevalent among children and have been shown to cause greater harm relative to adults. ${ }^{7,8}$ These differences may be due to weight-based dosing in pediatrics, use of different formulations, and the inability of children to identify or communicate potential medication discrepancies. The role of medication reconciliation in this setting remains unclear. ${ }^{9,10}$

Medication reconciliation is defined as the process of creating a complete and accurate list of the patient's current home medications, known as a best possible medication history (BPMH), and comparing that list against the patient's admission, transfer, and discharge medication orders. ${ }^{11}$ Medication discrepancies identified through reconciliation are resolved with the prescriber, including documentation of the discrepancies themselves and how they were resolved. ${ }^{11}$ The potential effect of medication reconciliation is significant, with studies showing a $70 \%$ to $80 \%$ reduction in medication discrepancies and adverse drug events. ${ }^{12-14}$ Medication reconciliation is a required organizational practice of Accreditation Canada ${ }^{15}$ and is included as an indicator on the study institution's Quality Improvement Plan (as required by Ontario's Excellent Care for All Act, 2010). ${ }^{16}$ The process of medication reconciliation is endorsed by leading international patient safety organizations as a patient safety priority and indicator in both Canada and the United States. ${ }^{16-20}$

Medication reconciliation on admission was implemented hospital-wide at the study institution (The Hospital for Sick Children in Toronto, Ontario) in July 2008. The admitting physician or nurse practitioner obtains an initial medication history and then documents, on a paper-based form (Appendix 1, available at www.cjhp-online.ca/index.php/cjhp/issue/view/ 107/show Toc), the intent to continue, discontinue, hold, or change each home medication upon admission. The nurse then obtains the BPMH and reconciles it with admission orders, following a retroactive model of medication reconciliation. ${ }^{11}$ Identified discrepancies are resolved with the responsible prescriber. Because of limited resources, clinical pharmacists are available for consultation only if needed. Transfer medication reconciliation was implemented hospital-wide in January 2011; it involves the completion of both admission and transfer medication reconciliation forms (Appendixes 1 and 2, available at www.cjhp-online.ca/index.php/cjhp/issue/view/107/showToc) at each internal transition of care. The admitting physician or nurse practitioner is responsible for documenting the intent regarding home and transferring unit medications and for writing transfer medication orders, with the nurse and/or pharmacist completing the reconciliation.

Although medication reconciliation performed by pharmacists is preferable, given their specialized knowledge of medications and their patient interviewing skills, human resource limitations render them less available to do so for every admitted patient. ${ }^{3,5,14}$ Pharmacy technicians are in a unique position to perform medication reconciliation, given their familiarity with medication names, strengths, formulations, and dosing schedules for prescription and over-the-counter medications. ${ }^{21,22}$ The ability of pharmacy technicians to obtain BPMHs on admission has been demonstrated, with studies showing a reduction in potential medication discrepancies for adult patients in the hospital setting. ${ }^{2,13,23-31}$ Despite these findings, there is currently no published literature describing the role of pharmacy technicians in obtaining BPMHs and performing reconciliation, at both the admission and transfer interfaces of care, in a pediatric tertiary care hospital.

The aim of this study was to develop, implement, and evaluate an innovative medication reconciliation program in which a trained pharmacy technician, available 5 days a week, 
obtained BPMHs and performed admission and transfer medication reconciliation for pediatric patients admitted to the Cardiology ward and the Cardiac Critcal Care Unit (CCCU) at The Hospital for Sick Children. The primary objective of this study was to evaluate the effectiveness of medication reconciliation by comparing the completeness and accuracy of BPMHs and reconciliation performed by a pharmacy technician (pilot) with nurses and/or pharmacists (baseline; current standard of practice at the study institution, as described above). A secondary objective was to determine the severity of unintentional discrepancies.

\section{METHODS}

In this prospective cohort comparison study, medication reconciliation was performed by nurses or pharmacists (baseline) and by a trained pharmacy technician (pilot) in the Cardiology ward and the CCCU. Baseline and pilot study data were collected by a pharmacy resident (R.W.) for 3 weeks during each study phase. The study was approved by the Research Ethics Board of The Hospital for Sick Children. Written informed consent for participation in the study was obtained from children's parents or guardians.

Patients 18 years of age and younger who were admitted to the Cardiology ward or the CCCU or who were transferred between these units during the study periods were eligible for the study. The sample size of the study was based on convenience. Patients were excluded if they were off-service patients residing on the Cardiology ward or in the CCCU, if they had been transferred from another unit, if they had been admitted to the Cardiology ward for a planned catheterization procedure with less than $24 \mathrm{~h}$ length of stay, or if they had been admitted to or transferred between the Cardiology ward and the CCCU between Friday at 1600 and Sunday at 1200 (when the pharmacy technician was not available). Patients for whom the pharmacy resident could not perform a medication reconciliation audit within $48 \mathrm{~h}$ of admission and/or transfer were excluded, as were patients whose parents or guardians declined participation.

One pharmacy technician was recruited for the study via an internal job posting and interview process. The pharmacy technician selected was trained for 5 days by the pharmacy resident and clinical pharmacist (C.C.) to conduct a BPMH and to perform medication reconciliation.

To ensure that the pharmacy resident was competent to conduct and audit medication reconciliation, the resident completed an off-site certification program at a tertiary care teaching hospital.

To determine the completeness and accuracy of the institution's medication reconciliation process at baseline, the pharmacy resident completed a 3-week audit for eligible patients. Quality audits of medication reconciliation on admission involved reinterviewing patients and/or their families to verify the BPMH collected and the reconciliation performed by nurses. Quality audits of medication reconciliation on transfer involved reconciliation of transfer medication orders with the BPMH and the medications ordered by the transferring unit. Each audit was completed within $48 \mathrm{~h}$ after the patient's admission to or transfer between the wards. The 48-h timeframe was chosen to give the pharmacy resident sufficient time to conduct audits, while being short enough to minimize potential recall bias and to allow any identified discrepancies to be resolved in a timely manner.

During the 3-week pilot phase, medication reconciliation for patients who met the inclusion criteria was performed by the pharmacy technician instead of being performed by nurses or pharmacists. The pharmacy technician was available to perform admission and transfer medication reconciliation on weekdays (Monday to Friday) between 0800 and 1600. For eligible patients who were admitted or transferred between 1600 and 0800 on weekdays and between 1200 on Sunday and 0800 on Monday, the pharmacy technician completed medication reconciliation the next morning. Discrepancies identified by the pharmacy technician were discussed with the pharmacy resident, who then approached the responsible prescriber for clarification. The pharmacy resident then performed an audit, similar to audits in the baseline phase. To minimize recall bias, the order in which medication interviews were conducted by the pharmacy technician and the pharmacy resident was alternated, with a minimum 4-h interval between interviews for any particular patient. To allow for blinding of the pharmacy resident's BPMH from the pharmacy technician, the pharmacy resident used a separate medication reconciliation form for auditing purposes.

The completeness of BPMHs obtained on admission by nurses or pharmacists (baseline) and by the pharmacy technician (pilot) was assessed by whether signatures were documented on the medication reconciliation form within $24 \mathrm{~h}$ of admission. The accuracy of health care practitioners' BPMHs was measured by comparison with the pharmacy resident's BPMHs for the same patients, in terms of the number of omissions or discrepancies in drug name, dosage, route, frequency, or formulation. The completeness of reconciliation of the BPMH against admission and transfer orders performed by nurses or pharmacists and by the pharmacy technician was assessed by whether signatures were documented on the admission and transfer medication reconciliation forms within $24 \mathrm{~h}$ of the admission or transfer. The accuracy of reconciliation performed by health care practitioners was measured by comparison with the pharmacy resident's reconciliation for the same patients, in terms of number and types of discrepancies (no discrepancy, intentional discrepancy, undocumented intentional discrepancy, unintentional discrepancy). The types of unintentional discrepancies (omission, commission, wrong drug, wrong dose, wrong route, wrong frequency) were measured and compared. To ensure that patient safety standards were met, the pharmacy resident and clinical 
pharmacists resolved any discrepancies identified with the responsible prescriber within $48 \mathrm{~h}$ of admission or transfer.

To determine the clinical importance of unintentional discrepancies in causing patient harm or clinical deterioration, 2 CCCU staff physicians and 1 Cardiology staff physician (J.R.) independently rated the severity of unintentional discrepancies using a 3-point scale published by Cornish and others. ${ }^{6}$ The rating physicians were blinded as to the study phase in which the unintentional discrepancy occurred. Disagreements in severity ratings were resolved by discussion among the 3 physicians.

Data were entered into Microsoft Excel 2007 software (version 2006; Microsoft Corporation, Redmond, Washington) and subsequently analyzed by SAS (version 9.1, SAS Institute Inc, Cary, North Carolina) to generate descriptive statistics. These descriptive statistics were used to summarize patient demographic characteristics and the characteristics of patients' home medications. Completeness and accuracy parameters were compared with nonparametric statistical tests (the Wilcoxon rank-sum test and the Fisher exact test). Statistical significance was defined as $p<0.05$. Inter-rater reliability for assessment of severity of unintentional discrepancies was assessed by the kappa statistic.

\section{RESULTS}

Of the 141 patients admitted to and/or transferred between the Cardiology ward and the CCCU during the two 3-week audit periods, 84 were eligible for inclusion in the study. During the 3-week baseline phase (February 14 to March 4, 2011), 38 patients met the inclusion criteria. Any single patient could undergo multiple transfers during one hospital stay, with each medication reconciliation event being referred to as an episode. As such, 34 BPMHs, 33 episodes of admission reconciliation, and 18 episodes of transfer reconciliation were audited by the pharmacy resident during the baseline audit. During the 3-week pilot phase (March 7 to 25, 2011), 46 patients met the inclusion criteria, and 27 BPMHs, 20 episodes of admission reconciliation, and 34 episodes of transfer reconciliation were audited. Notably, the number of patients in each phase was not the same as the number of BPMHs audited. Some patients experienced multiple transfer episodes, and BPMHs for others were completed by nurses before the pharmacy technician's intervention during the pilot phase. These cases were included for reconciliation audits only.

\section{Demographic and Home Medication Characteristics}

The age of patients included in the 2 phases of the study was similar, and both samples had more boys than girls (Table 1). The percentage of patients not taking any prescription or nonprescription medications at home was significantly higher in the baseline phase than in the pilot phase (18\% [7/38] versus $7 \%$ [3/46], $p=0.043)$. Conversely, the percentage of patients taking more than 3 prescription and/or nonprescription medications was significantly higher in the pilot phase than in the baseline phase (52\% [24/46] versus 29\% [11/38], $p=0.043)$.

Table 1. Demographic Characteristics and Home Medications

\begin{tabular}{|c|c|c|c|c|}
\hline \multirow{3}{*}{$\begin{array}{l}\text { Characteristic } \\
\text { Age (median and range) }\end{array}$} & \multicolumn{4}{|c|}{ Group; No. (\%) of Patients* } \\
\hline & \multicolumn{2}{|c|}{ Baseline $(n=38)$} & \multicolumn{2}{|c|}{ Pilot Study $(n=46)$} \\
\hline & $9.0 \mathrm{mo}$ & (1 $\mathrm{d}$ to $17 \mathrm{yr}$ ) & $5.9 \mathrm{mo}$ & (3 d to $16 \mathrm{yr}$ ) \\
\hline Sex, male & 26 & (68) & 28 & $(61)$ \\
\hline \multicolumn{5}{|l|}{ Medical condition } \\
\hline $\begin{array}{l}\text { Congenital heart defect: } \\
\text { single ventricle }\end{array}$ & 5 & (13) & 13 & $(28)$ \\
\hline $\begin{array}{l}\text { Congenital heart defect: } \\
\text { non-single ventricle }\end{array}$ & 26 & (68) & 25 & $(54)$ \\
\hline Heart failure (cardiomyopathy) & 3 & (8) & 5 & $(11)$ \\
\hline Othert & 4 & $(11)$ & 3 & (7) \\
\hline \multicolumn{5}{|l|}{ Total no. of home medications } \\
\hline $0 \neq$ & 7 & (18) & 3 & (7) \\
\hline 1 & 6 & (16) & 7 & $(15)$ \\
\hline 2 & 7 & $(18)$ & 7 & $(15)$ \\
\hline 3 & 7 & (18) & 5 & $(11)$ \\
\hline$>3 \neq$ & 11 & (29) & 24 & $(52)$ \\
\hline \multicolumn{5}{|l|}{$\begin{array}{l}\text { No. of home medications } \\
\text { per patient (median and range) }\end{array}$} \\
\hline Prescription & 1.5 & $(0-8)$ & 2.5 & (15) \\
\hline Nonprescription & 1.0 & $(0-4)$ & 0 & $(0-5)$ \\
\hline
\end{tabular}

*Except where indicated otherwise.

†Arrhythmia, infection, seizures, hyponatremia, hypercholesterolemia, pulmonary hypertension.

\#Significant difference, $p<0.05$. 


\section{Completeness and Accuracy of BPMH}

There was no significant difference in the completion of BPMHs within $24 \mathrm{~h}$ after admission between the baseline and pilot phases (82\% [28/34] versus 78\% [21/27], $p=0.75$ ). However, completion of BPMHs within $48 \mathrm{~h}$ of admission was significantly higher during the pilot phase than during the baseline phase (100\% [27/27] versus 82\% [28/34], $p=0.030)$.

No significant difference in the proportion of patients with at least one BPMH discrepancy was found between the 2 phases (38\% [13/34] for baseline versus 22\% [6/27] for pilot, $p=0.27$ ). Specifically, 19 BPMH discrepancies were identified during the baseline phase (Figure 1) and 6 during the pilot phase (Figure 2). The most common type of BPMH discrepancy during both phases was omission of a medication.

\section{Completeness and Accuracy of Admission and Transfer Reconciliation}

No significant difference in the completion of admission reconciliation within $24 \mathrm{~h}$ of admission was found between the

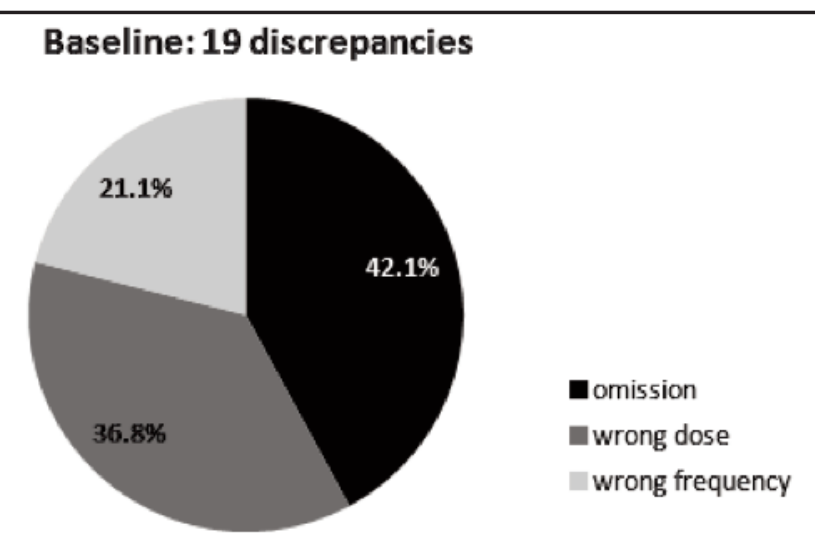

Figure 1. Types of best possible medication history discrepancies identified during baseline phase.

\section{Pilot: 6 discrepancies}

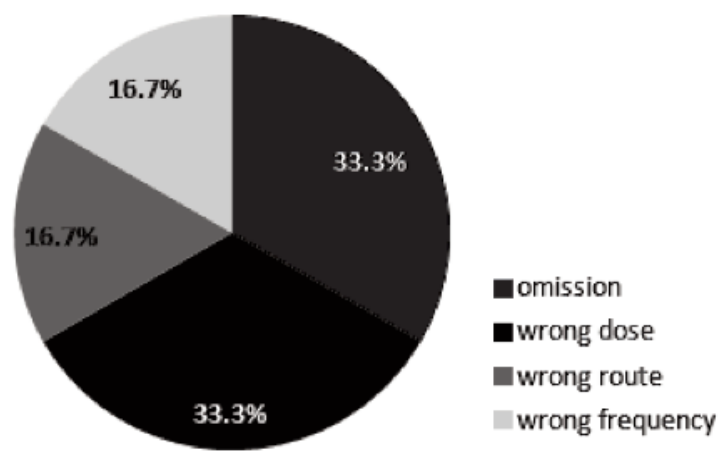

Figure 2. Types of best possible medication history discrepancies identified during pilot phase. baseline and pilot phases (70\% [23/33] versus 75\% [15/20], $p=$ 0.76). A significantly higher proportion of transfer reconciliation episodes were completed within $24 \mathrm{~h}$ of the transfer during the pilot phase than during the baseline phase $(91 \%$ [31/34] versus $61 \%[11 / 18], p=0.022)$. The proportion of patients with at least one unintentional discrepancy did not differ significantly between the 2 phases for either admission or transfer interfaces of care (Table 2). The mean number of unintentional discrepancies per patient was lower during the pilot phase than during the baseline phase (0.07 versus 0.37 ).

During the baseline phase, 14 unintentional discrepancies were identified. Eight of these were omissions on the BPMH, 4 were wrong doses, and 2 involved wrong frequencies. Of these 14 unintentional discrepancies, 12 occurred during admission and 2 during transfers. During the pilot phase, 3 unintentional discrepancies were identified: 2 omissions and 1 wrong dose. Two of these occurred during admission and the other occurred during a transfer. The largest category of unintentional discrepancies identified during the baseline phase was vitamins (5/14 [36\%]). During the pilot phase, the 3 unintentional discrepancies involved an anti-infective agent (nitrofurantoin), melatonin, and a vitamin supplement, respectively.

\section{Severity of Unintentional Discrepancies}

A total of 17 unintentional discrepancies were identified, but for the purposes of rating severity, the discrepancies were grouped according to individual medication orders. One medication order was associated with 2 unintentional discrepancies (wrong dose and wrong frequency), and therefore ratings were determined for only 16 unintentional discrepancies.

There was fair inter-rater reliability for the rating of unintentional discrepancies (kappa $=0.2[95 \%$ confidence interval -0.3 to 0.7$]$ ). Although there was disagreement in severity classification for $5(31 \%)$ of the 16 discrepancies that were rated as unintentional, consensus was achieved through discussion among the 3 raters. The majority of the unintentional discrepancies $(n=15[94 \%])$ were rated as class I (unlikely to cause patient discomfort or clinical deterioration). The other unintentional discrepancy $(n=1[6 \%])$ was rated as class II (having potential to cause moderate discomfort or clinical deterioration). None of the unintentional discrepancies were rated as class III (potential to cause severe discomfort or clinical deterioration) (Appendix 3, available at www.cjhp-online.ca/ index.php/cjhp/issue/view/107/showToc). ${ }^{6}$

\section{DISCUSSION}

To the authors' knowledge, this work represents the first study to investigate the potential role of pharmacy technicians in medication reconciliation in a pediatric teaching hospital, specifically to obtain BPMHs and perform reconciliation at both the admission and transfer interfaces of care. 
Table 2. Accuracy of Admission and Transfer Reconciliation

\begin{tabular}{lcccccccccc} 
Medication Group & \multicolumn{3}{c}{$\begin{array}{c}\text { No. (\%) of Episodes at Admission } \\
\text { Reconciliation* }\end{array}$} & & \multicolumn{3}{c}{ No. (\%) of Episodes at Transfer } \\
Reconciliation*
\end{tabular}

*Percentages within any column do not sum to 100 as each admission or transfer might be associated with more than one type of discrepancy.

tFor all but the first row, data refer to episodes with at least one of the specified type of discrepancy.

fIntentional discrepancy: the prescriber made an intentional choice to add, change, or discontinue a medication, and this choice is clearly documented. ${ }^{11}$

§Undocumented intentional discrepancy: the prescriber made an intentional choice to add, change, or discontinue a medication, but this choice is not clearly documented. ${ }^{11}$

ףUnintentional discrepancy: the prescriber unintentionally changed, added, or omitted a medication that the patient was taking before admission. ${ }^{11}$

One potential benefit of involving pharmacy technicians in medication reconciliation is identification of unintentional discrepancies in time to prevent associated adverse drug events. Compared with adults, children are at greater risk of medication errors and potential adverse drug events as a result of individualized weight-based dosing, differences in compounded formulations and concentrations that may be dispensed from different community pharmacies, and confusion between units of measure for liquid medications (e.g., caregivers often report the volume of drug administered in millilitres, rather than the actual amount of drug in milligrams). Kaushal and others ${ }^{9}$ showed that the rate of potential adverse drug events was 3 times higher in a pediatric population than an adult population. In certain instances, children may be taking fewer medications than adults; however, the impact of medication discrepancies may be more significant in children than in adults. For instance, children may not be able to articulate the adverse effects they are experiencing and may be less able to endure complications arising from medication errors because their internal reserves are more limited. ${ }^{9}$ Sources of BPMHs can also differ between adult and pediatric settings. Pediatric practitioners typically rely on the child's caregiver when obtaining a BPMH, and, depending on the circumstances, the interviewee may not be the caregiver who administers the child's medications. In the context of these challenges, the pediatric population would benefit from focused attention on medication reconciliation. Other potential benefits of medication reconciliation by a pharmacy technician include a reduction in the time that health care providers spend on technical tasks related to information retrieval during admissions, development of collaborative practice models, and enhanced job satisfaction. ${ }^{32}$ Creating positions to facilitate medication reconciliation is also in line with the expanding roles of registered pharmacy technicians.

The percentage of BPMHs completed within $24 \mathrm{~h}$ of admission was slightly lower during the pilot phase than during the baseline phase, but the difference was not statistically significant. Delays in completion of a BPMH while awaiting completion of the initial medication history by the prescriber posed a challenge to the pharmacy technician, who strictly followed the retroactive model of medication reconciliation; this was especially true in the CCCU setting. Potential reasons for these delays included difficulty in approaching families during high-acuity circumstances and the lower priority that physicians may give to medication reconciliation when faced with acute patient care activities. Having more than one pharmacy technician available for medication reconciliation over extended hours during the day could allow for better capture of BPMHs within the target timeframe. Notably, the pharmacy technician achieved $100 \%$ completion of BPMHs by $48 \mathrm{~h}$ after admission, yet completion of the BPMH by nurses and/or pharmacists was the same at 24 and $48 \mathrm{~h}$ after admission.

No significant difference was found between the 2 phases in the proportion of patients with at least one BPMH discrepancy, although there was a trend toward a smaller proportion in the pilot phase. The proportion of patients taking more than 3 prescription and/or nonprescription medications at home was significantly greater during the pilot phase, and the proportion of patients taking no home medications was significantly greater during the baseline phase. These findings suggest that the pharmacy technician encountered more complex home medication regimens, yet was able to obtain BPMHs with accuracy comparable to that of nurses and pharmacists. Omissions were the most common type of BPMH discrepancy identified in both phases, consistent with findings from previous studies. ${ }^{30,33}$

This study found no significant difference in the completion of admission reconciliation between the baseline and pilot phases, although the percentage of completion was higher during the pilot. The percentage of completed transfer reconciliation episodes was significantly higher during the pilot phase, which 
supports the focused role of a pharmacy technician; in contrast, nurses have multiple direct patient care duties when receiving a patient on transfer.

There was no significant difference between the baseline and pilot phases in the percentage of patients with at least one unintentional discrepancy for both admission and transfer reconciliation. This finding exemplifies the capability of a trained pharmacy technician to perform medication reconciliation to facilitate the goal of reducing medication discrepancies and potential adverse drug events. The pharmacy technician was able to identify home medications that had been omitted and to clarify details of medication regimens using various resources that had been introduced during her training. The mean number of unintentional discrepancies per patient was lower during the pilot phase than during the baseline phase. The mean number during the pilot phase was also lower than that reported by another centre using pharmacy technicians for medication reconciliation, for which the reported mean number of unintentional discrepancies per patient was $0.24 . .^{30}$ It was reassuring that all but 1 of 16 unintentional discrepancies were rated as unlikely to cause patient discomfort or clinical deterioration (i.e., class I discrepancy). The remaining discrepancy, identified during the baseline phase, was considered to have the potential to cause moderate discomfort or clinical deterioration (i.e., class II discrepancy).

The study had several limitations. Because of time constraints, the pharmacy resident could collect data for only 3 weeks during each phase, which resulted in small sample sizes and a lack of power to detect statistically significant associations for secondary objectives of interest, such as determination of variables associated with a higher rate of unintentional discrepancies. Future studies should address this limitation to allow identification and subsequent minimization of factors associated with unintentional discrepancies. The study did not involve randomization or matching of groups and thus could not account for significant differences in the number of medications encountered in each group. However, a randomized controlled trial would not be practical from a logistic standpoint, and randomization could lead to delays in medication reconciliation, thereby compromising patient safety.

During the pilot phase, limited availability of the pharmacy technician could have led to delays in completing medication reconciliation within $24 \mathrm{~h}$ for some patients, particularly while waiting for the prescriber to complete the initial history. The retroactive model of medication reconciliation, whereby a primary history is created and used to generate admission medication orders before the BPMH is obtained, may have hindered the pharmacy technician's ability to obtain BPMHs in a timely manner. Although a proactive model of medication reconciliation, in which the BPMH is created first, would be ideal, the study institution primarily follows a retroactive model. Only in high-acuity settings, such as in the CCCU during the baseline phase, is a mixed model (retroactive and proactive) of medication reconciliation practised by nurses. Future studies should assess medication reconciliation by pharmacy technicians in the context of a mixed model.

To minimize recall bias, the pharmacy resident and pharmacy technician alternated the order in which they interviewed patients and families. Alternating the order of interviews was not feasible during the baseline phase because of the pharmacy resident's limited availability during this period, which might have caused delays in medication reconciliation. During the pilot phase, the pharmacy technician may have had an advantage in cases where the pharmacy resident interviewed patients and families first.

Generalizability of this practice model to other areas of the study hospital is currently limited, as only one pharmacy technician was trained to perform medication reconciliation within the Cardiology ward and the CCCU, and this person has limited availability to perform this task. The pharmacy technician had extensive experience as a CCCU-based pharmacy technician and was therefore accustomed to communicating with a variety of health care providers and to navigating the patient ward. Training of other non-ward-based pharmacy technicians to perform medication reconciliation would have to take into account these differences in work experience. It would be useful for institutions to develop a standardized medication reconciliation certification program to formally train their pharmacy technicians.

\section{CONCLUSION}

This study has shown that a trained pharmacy technician can perform medication reconciliation for pediatric cardiology patients with completeness and accuracy comparable to those achieved by nurses and pharmacists at both admission and transfer interfaces of care. This practice model places patient safety at the forefront while maximizing the utilization of existing human resources. Future studies should explore expansion of this practice model to other areas of the hospital for extended hours and days, as well as determining its sustainability and costeffectiveness. This model could be adopted by other pediatric institutions interested in using pharmacy technicians to perform medication reconciliation.

\section{References}

1. Coffey M, Mack L, Streitenberger K, Bishara T, De Faveri L, Matlow A. Prevalence and clinical significance of medication discrepancies at paediatric hospital admission. Acad Pediatr. 2009;9(5):291-2.

2. Remtulla S, Brown G, Frighetto L. Best possible medication history by a pharmacy technician at a tertiary care hospital. Can J Hosp Pharm. 2009;62(5):402-5.

3. Leung M, Jung J, Lau W, Kiaii M, Jung B. Best possible medication history for hemodialysis patients obtained by a pharmacy technician. Can J Hosp Pharm. 2009;62(5):386-91.

4. Baker GR, Norton PG, Flintoft V, Blais R, Brown A, Cox J, et al. The Canadian Adverse Events Study: the incidence of adverse events among hospital patients in Canada. CMAJ. 2004;170(11):1678-86. 
5. Tam VC, Knowles SR, Cornish PL, Fine N, Marchesano R, Etchells EE. Frequency, type and clinical importance of medication history errors at admission to hospital: a systematic review. CMAJ. 2005;173(5):510-5.

6. Cornish PL, Knowles SR, Marchesano R, Tam V, Shadowitz S, Juurlink $\mathrm{DN}$, et al. Unintended medication discrepancies at the time of hospital admission. Arch Intern Med. 2005;165(4):424-9.

7. Ghaleb MA, Barber N, Franklin BD, Wong IC. The incidence and nature of prescribing and medication administration errors in paediatric inpatients. Arch Dis Child. 2010;95(2):113-8.

8. Wong IC, Ghaleb MA, Franklin BD, Barber N. Incidence and nature of dosing errors in paediatric medications: a systematic review. Drug Saf. 2004;27(9):661-70.

9. Kaushal R, Bates DW, Landrigan C, McKenna KJ, Clapp MD, Federico F, et al. Medication errors and adverse drug events in pediatric inpatients. JAMA. 2001;285(16):2114-20.

10. Huynh C, Wong IC, Tomlin S, Terry D, Sinclair A, Wilson K, et al. Medication discrepancies at transitions in pediatrics: a review of the literature. Paediatr Drugs. 2013;15(3):203-15.

11. Medication reconciliation in acute care: getting started kit. Version 3.0 . Edmonton (AB): Canadian Patient Safety Institute; 2012 [cited 2013 Feb 17]. Available from: www.saferhealthcarenow.ca/EN/Interventions/medrec/ Documents/Acute\%20Care/MedRec\%20(Acute\%20Care)\%20Getting\%2 0Started\%20Kit.pdf

12. Whittington J, Cohen H. OSF Healthcare's journey in patient safety. Qual Manag Health Care. 2004;13(1):53-9.

13. Michels RD, Meisel S. Program using pharmacy technicians to obtain medication histories. Am J Health Syst Pharm. 2003;60(19):1982-6.

14. Gardner B, Graner K. Pharmacists' medication reconciliation-related clinical interventions in a children's hospital. Jt Comm J Qual Patient Saf. 2009;35(5):278-82.

15. Required organizational practices 2012. Ottawa (ON): Accreditation Canada; 2012 [cited $2013 \mathrm{Feb}$ 17]. Available from: www.accreditation.cal accreditation-programs/qmentum/required-organizational-practices/

16. Excellent care for all. Toronto (ON): Ontario Ministry of Health and Long-Term Care; 2008 [cited 2013 Feb 17]. Available from: http:// health.gov.on.ca/en/public/programs/ecfa/default.aspx/

17. How-to guide: prevent adverse drug events (medication reconciliation). Cambridge (MA): Institute for Healthcare Improvement; 2013 [cited 2013 Feb 17]. Available from: www.ihi.org/knowledge/Pages/Tools/Howto GuidePreventAdverseDrugEvents.aspx

18. Tools and resources. Edmonton (AB): Canadian Patient Safety Institute; 2012 [cited 2012 July 10]. Available from: www.patientsafetyinstitute.ca/ English/toolsResources/Pages/default.aspx

19. Building a case for medication reconciliation. Acute Care ISMP Med Saf Alert. 2005 [cited 10 Jul 2012]. Available from: www.ismp.org/newsletters/ acutecare/articles/20050421.asp

20. Hospital: 2013 national patient safety goals. Oak Brook (IL): The Joint Commission; 2013 [cited 10 Jul 2012]. Available from: www. jointcommission.org/standards_information/npsgs.aspx

21. Koch KE, Weeks A. Clinically orientated pharmacy technicians to augment clinical services. Am J Health Syst Pharm. 1998;55(13):1375-81.

22. Weber E, Hepfinger C, Koontz R, Cohn-Oswald L. Pharmacy technicians supporting clinical functions. Am J Health Syst Pharm. 2005;62(23):246672.

23. Patel NH, Onatade R. Development of a ward-based technician service over the past two years at a London teaching hospital [abstract]. In: 41st Midyear Clinical Meeting, American Society of Health-System Pharmacists; 2006 Dec 3-7.

24. Turner SJ, Lam SS, Leung BK, Toll CT. Establishing the role of a clinical pharmacy technician. J Pharm Pract Res. 2005;35(2):119-21.

25. Tizard J. Taking drug histories — an audit of technician accuracy. Hosp Pharm. 2007;14(10):351-2.

26. Fockler S, Mann JL. Advancing pharmacy services in the midst of pharmacist shortages [abstract]. Can J Hosp Pharm. 2007;60 Suppl 2:34.
27. Saulnier $\mathrm{L}$, White $M$. Technicians and pharmacists partnering for successful medication reconciliation [abstract]. Can J Hosp Pharm. 2007;60 Suppl 2:29

28. van den Bemt PM, van den Broek S, van Nunen AK, Harbers JB, Lenderink AW. Medication reconciliation performed by pharmacy technicians at the time of preoperative screening. Ann Pharmacother. 2009;43(5):868-74.

29. Knight H, Edgerton L, Foster R. Pharmacy technicians obtaining medication histories within the emergency department. Am J Health Syst Pharm. 2010;67(7):512-4.

30. Johnston R, Saulnier L, Gould O. Best possible medication history in the emergency department: comparing pharmacy technicians and pharmacists. Can J Hosp Pharm. 2010;63(5):359-65.

31. Gardella JE, Cardwell TB, Nnadi M. Improving medication safety with accurate preadmission medications lists and postdischarge education. Jt Comm J Qual Patient Saf. 2012;38(10):452-8.

32. Saulnier L. Should pharmacy technicians be trained to obtain medication histories and provide discharge counselling? The "pro" side. Can J Hosp Pharm. 2008;61(6):441-2.

33. Baker GR, Norton PG. Adverse events and patient safety in Canadian health care. CMAJ. 2004;170(3):353-4

Carol Chan, BScPhm, ACPR, RPh, is with the Department of Pharmacy, The Hospital for Sick Children, Toronto, Ontario.

Renée Woo, BScPhm, ACPR, RPh, is with the Department of Pharmacy, The Hospital for Sick Children, Toronto, Ontario.

Winnie Seto, BScPhm, PharmD, MSc, ACPR, RPh, is with the Department of Pharmacy, The Hospital for Sick Children, Toronto, Ontario.

Sandra Pong, BSCPhm, PharmD, ACPR, RPh, is with the Department of Pharmacy, The Hospital for Sick Children, Toronto, Ontario.

Tessie Gilhooly, RN, MN, is with the Quality and Risk Management Department, The Hospital for Sick Children, Toronto, Ontario.

Jennifer Russell, MD, FRCPC, is with the Division of Cardiology, The Hospital for Sick Children, Toronto, Ontario.

Competing interests: None declared.

\section{Address correspondence to:}

Carol Chan

Department of Pharmacy

The Hospital for Sick Children

555 University Avenue

Toronto ON M5G 1X8

e-mail: carol.chan@sickkids.ca

Acknowledgements: The authors would like to thank Donna Alonzi, pharmacy technician, for her effort in making this project a success, and Dr Afrothite Kotsakis and Dr Tilman Humpl for their time and expertise in rating the severity of unintentional discrepancies. The authors would also like to thank Lauza Saulnier for sharing her research experience in this field; Olavo Fernandes and Karen Cameron for providing medication reconciliation resources and certification; Cyntra Mascarenhas and Angie Thiessen, clinical pharmacists, for facilitating project communications on the Cardiology ward and the Cardiac Critical Care Unit; and Annie Dupuis for her expertise with the statistical analysis.

Funding: This study was funded by the SickKids Labatt Family Heart Centre Innovations Fund. 